\title{
Literacy for the Health of Refugees - Broadly Speaking
}

\author{
by Ann Goldblatt*
}

\section{Introduction}

An alliance of health workers and refugee advocates to promote literacy has yet to be maximized. The significance of literacy for agency-based refugee advocates and second language educators is not simply that people are able to decipher written English. By full definition, literacy is knowing the "ways of the world," and assuming a strong role within it. Similarly, the attention of health workers to literacy ought to open into a wider concern for how people understand their health, the systems which influence it, and their ability to make choices in those areas which affect their health. The mandates of both health and refugee workers requires and legitimizes activity bases on this broader notion of literacy as education for social justice. With movement in this direction in the health field, refugee advocates can call upon health workers as partners in this process of change.

\section{Alberta players}

The pattern of refugees coming into Alberta in the 1980s mirrors that of other parts of Canada, with the major countries of origin being Vietnam and $\mathrm{El}$ Salvador. A recent influx has come from Poland. From highest to lowest, the source countries for immigrants and refugees to Alberta in 1988 were Hong Kong, Vietnam, India, the Philippines, China, Poland, the US, Brunei, England and El Salvador, for a total of 14,025 , according to Canada Employment and Immigration statistics.

In 1987, the total number of immigrants to Alberta was 12,000 , representing 8 per cent of the national total. Almost 20 per cent of Alberta residents are foreign-born and, in the 1986 census on ethnic origin, 51 per cent of Albertans traced their ancestry to Britain, 8 per cent to Germany, 5 per cent to the Ukraine and 5 per cent to France.

Though Edmonton and Calgary receive 85 per cent of newcomers, the relatively small percentage of non-English speaking people in relation to the total population has an influence on the service response. There is a reluctance to sacrifice total population services for the benefit of special constituencies. Nevertheless, the concentration of immigrants and refugees within particular neighbourhoods of Edmonton has led to a reexamination of "mainstream" service delivery in those areas.

The political climate in Alberta is one in which individualism and free enterprise are held high. Those who succeed do so, it is argued, because they have worked hard to get where they are. Minimal government intervention is the preferred mode. Volunteers make a large contribution to service delivery and community organizations are called upon to contribute generously to the well-being of citizens.

Edmonton is something of an anomaly in this conservative environment,

\footnotetext{
* I am grateful for the hours spent thinking through the subject of refugees and literacy with Leo Campos, Manuel Rozental and Patricia Salegio, speaking from the "refugee perspective;" with Karen Barnes as an ESL educator; and with Margaret Third Tsuchima, working within a settlement agency. I take full responsibility for what is written but thank them for stimulating my thoughts through their frank reflections.
}

having elected almost a full slate of New Democrats provincially in the last two elections, and a politically progressive mayor in the most recent municipal election in 1989.

Public recognition of culture is primarily of the food and dance phenomenon, along with school-based Heritage Language programs. Edmonton has, for a number of years, hosted a two-day Heritage days festival on the August long weekend, called Heritage days, which attracts gastronomic and arts appreciators by the thousands to partake of the foods, crafts and entertainment of community members of some 30 countries.

Alberta's formal support for refugees is handled through a network of settlement agencies which receive funding from Alberta Immigrant and Settlement Services within the Ministry of Career Development and Employment, and from the federal government. The settlement agencies in the Edmonton area function as community-based volunteer aid organizations whose mandate it is to provide an orientation to life in Alberta. Their services include English as a Second Language instruction, interpretation, counselling and assistance in finding accommodation and employment. Some have launched specific initiatives including a welcome house, Proyecto Salud, addressing violence against women in the Latin American communities, and a volunteer buddy system. The primary agencies are: Catholic Social Services, Changing Together: A Centre for Immigrant Women, Edmonton Immigrant Services Association, Indo-Canadian Women's Association, Mennonite Centre for Newcomers and St. Barnabas Refugee Society.

Human service organizations are becoming increasingly interested in 


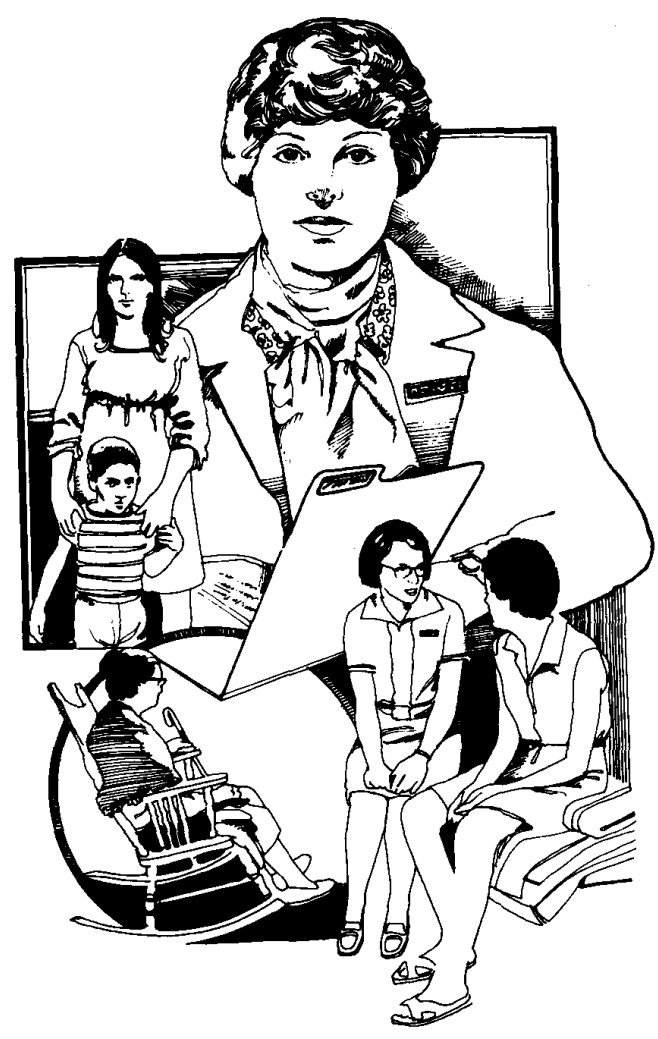

"targeting" multicultural communities, recognizing that priorities and program design have been oriented to generally healthier, white middle-class people who have benefitted most from the "universal" services. Over the past two years, the Edmonton Board of Health, the local public health agency, has focused on cross-cultural education for staff, researching natural ways of spreading information in cultural communities, and building a case for hiring trained interpreters. The issues have been tackled through the infrastructure of a crossdivisional committee on culture and health. Staffing and programming to reflect cultural needs are now being addressed, in relation to immigrants, refugees and Native people.

\section{The roles we play}

The mandates of second language educators, agency-based workers and health workers concerned with refugees, is to promote a high quality of life, with a focus on adjustment needs to life in Canada. How those mandates get interpreted is to emphasize "survival skills" which help people "fit in." Refugees are taught functional English so that they can use the buses, the bank, shop, etc.; they are oriented to the steps involved in securing the basic necessities of life and they are provided with health information with the expectation that they will make healthy choices for themselves and those in their care. Service providers see themselves as having a particular area of expertise, and, working against time pressures, they offer as much support in basic settlement as resources allow. Funding for ESL assumes that people require enough English to get minimal employment and get by in day to day functions.

The broader notion of "liberation literacy," articulated by Paulo Freire, in which the content of the education process is the real life experience of the learners and the purpose is to organize people to challenge social injustices, is believed to be beyond the parameters of institu- tional workers. Some of the reasons advanced include the sense that initial orientation to life in Canada should be optimistic, and not wallowing in the language of oppression. Further, there is a diversity of life experiences among refugees, depending upon their prior level of education and exposure to Western culture. Their experiences are not necessarily shared, and power imbalances extend to conflict between and within cultural communities. Many refugees who feel appreciative of the opportunity to live in a safe environment are reluctant to rock the boat for fear or reprisal.

Those workers whose salaries are tied to government wallet often do not feel free to be agitators for change. They worry about their own job security, particularly if the orientation is to point our government wrong-doings. Indeed, the curriculum and programs are subject to government approval.

The health field is in transition around the globe as people increasingly recognize the inability of sickness care services to prevent illness and promote health. There is also a growing emphasis on the uneven burden of ill health which falls upon those whose living and working conditions are unhealthy. Still, there have been decades of a heavy accent on expertise. Health professionals are trained with a specialized body of knowledge and see their responsibility as educating people without expert knowledge. Public health workers recognize people come with a set of beliefs, attitudes and behaviour but, in the limited time available, often feel compelled to provide as much information as possible rather than assume the position of a peer learner. Educators thus recognize the reality but feel powerless to address it directly. As a result, education tends to be removed from the social context that is the reality of refugees' lives.

\section{Impact on refugees}

The dramatic transitional experience of role changes, altered social status, isolation, child-like language limitations, 
job barriers, and discrimination, over and above traumatic experiences in the country of origin, has to be factored into the educational process. If not, much well-intentioned effort is probably lost. Refugees may minimize their contact with formal institutions if they do not believe their services to be relevant or accessible. They learn to accept their "fate," and, after acquiring basic orientation, may not have an opportunity to learn about how systems operate, who has power and how to go about challenging injustices by gaining political power.

\section{The mandates} of second language educators, agency-based workers and health workers concerned with refugees, is to promote a high quality of life, with a focus on adjustment needs to life in Canada. How those mandates get interpreted is to emphasize "survival skills" which help people "fit in."

\section{Strategies for change}

Rather than dismiss the potential to work in ways which do challenge the status quo where it is needed, it is important to look at who is in the best position to promote literacy that is a "reading of the world as well as of the world." Further, what can those who work within institutions contribute to the process without jeopardizing their jobs or stepping well beyond their mandates. Community groups and associations, if equipped with the necessary resources, may be in the best position to work in this manner. An example exists in the experience of the Latin American communities in Edmonton:

Supported by a short-term project through Planned Parenthood on reproductive health for new Canadians, a Latin American health committee brought together people who would not normally collaborate because of political differences. With a common perception of a breakdown in the health of the "community," the committee acted as a catalyst for dialogue to name what was "ailing" the communities in their "adaptation" to life in Canada and explore solutions collectively. Education on teen sexuality was the starting point, but it could not be considered apart from family relationships, which could not be considered in isolation from the social relations and considerations in the community at large.

The communities initiated a bi-weekly radio program in Spanish on the multilingual station, titled Salud. The program tackled sensitive issues on the cultural crises facing Latin Americans, and quickly built a large listening audience. The radio program spawned further dialogue. A Chilean popular education game designed to explore sexuality in a broad social context was used as a tool in housing cooperatives and other centres within Edmonton and Red Deer. A two-part workshop with parents and teens through a Spanish language and cultural school, Gabriela Mistral, delved into the struggles that characterize the adaptation experience and what was needed to resolve the problems. The cable television station has now requested that the Latin American communities begin a program modelled after the radio program Salud.

With a base of operation and funding channelled through a community agency, the communities were able to make progress
Refugees

are taught functional English so that they can use the buses, the bank, shop, etc.; they are oriented to the steps involved in securing the basic necessities of life and they are provided with health information with the expectation that they will make healthy choices for themselves and those in their care.

on their desire to name and analyze collective problems, and generate acceptable solutions.

The Latin American health committee members suggested that the best orientation can be given by those who have come through the refugee experience. They can impart realistic expectations and try to prevent some of the pitfalls which prove seriously detrimental to family and community well-being (e.g. overdependence upon services). They are also able to support refugees in building new dreams in place of shattered life aspirations. 
Institution-based health and refugee workers can support community groups to use these approaches. They can contribute a technical expertise, they can use the contacts in their sphere of influence with those in decisionmaking roles and funding bodies, they can contribute material resources (printing, copying, meeting space, etc.). While workers in any setting have distinct functions and skill areas, they can link with people in fields of practice which extend into other areas as partners for change.

It would be inappropriate for health workers expanding their sensitivity to literacy issues to narrowly interpret the need to be strictly adjusting the reading level of educational materials. There are certainly points where adjusted written information is critical. Full literacy implications, however, go far beyond taking what has been developed from and for a middle class social context and plugging it into a markedly different set of circumstances.

As an example, on the matter of prescription drugs, literacy and health documents, few as they are, point to the need to write dosage information and warnings in simple language. True, this is, but what appears on the surface to be a personal issue is also political: the refugee advocate can facilitate an exploration of who gets drugs prescribed, why and how are drugs marketed, pricing practices for generic versus brand name drugs, and the right to raise questions. Health workers are thus linking individual health and social conditions.

Nina Wallerstein, in her book Language and Culture in Conflict: Problemposing in the ESL Classroom, has applied Freire's concept of "liberation literacy" to second language instruction in San Francisco. She suggests that educators learn to listen and observe the cultural experience of the learners in the classroom and in the community, for example, by walking through neighbourhoods with the refugees as guides or by asking refugees to interview others in their community. The goal of the dialogue approach is to encourage critical thinking, following the cycle of naming the problem, understanding why it exists, and planning for action. It is built on the hope for a better life rather than being a matter of negative thinking.

She always begins by asking students "What can you teach me?" to reveal the assumption that everyone is a learner and that the production of knowledge is

\section{The broader} notion of "liberation literacy," articulated by Paulo Freire, in which the content of the education process is the real life experience of the learners and the purpose is to organize people to challenge social injustices, is believed to be beyond the parameters of institutional workers.

to be generated by their experience, they are more receptive to her approach. Thus, her orientation to housing, as an example, would address, as collective issues, questions like:

- Why do immigrants/refugees live in these neighbourhoods?

- Who sets rental rates? What are they based upon?
- Why are the services to these neighbourhoods different from other areas (cleanliness, snow-clearing)?

- Why are there ethnic tensions here? While individual health and refugee educators may already incorporate this approach, it is important that the institutions legitimize the reorientation to increase the value of their interventions.

\section{Conclusion}

Settlement issues are complex. People working within single mandates cannot effectively address the issues. Hence, coordination and partnerships are critical for removing inequities. Those located within institutional settings have an obligation to design their work to reflect the real life and social context of those whose well-being is their concern. Linkages must be strengthened between the multiple players who advocate for refugees toward optimal rather than minimal living standards.

The "liberation literacy" popular education model is grounded in the same set of principles and assumptions as community development. Thus, it calls upon refugee advocates, in all human service settings, to act as facilitators for and contributors to a process of social change where the constituency affected assumes control over decisions. Agreement upon the nature of the refugee experience and appropriate action on the barriers is accompanied by a clear definition of roles and interests.

Given some reorientation in this direction among health workers, the timing is ripe for refugee workers to look to them as allies. The process of building partnerships takes time but the time is well spent because the quality of people's lives is compromised in their absence.

Ann Goldblatt is a consultant in the Health Promotion Division of the Edmonton Board of Health. Her primary role is bridging the public health mandate with a social agenda through the principles of community development. 